\title{
A Patient with Cervical Swelling
}

\author{
Mete Bilgul ${ }^{1}$, Yemisen Mücahit ${ }^{1}$, Demirel Aslıhan Ertaban ${ }^{1,2}$ and Tabak Fehmi ${ }^{1}$
}

Key words: tularemia, cervical swelling

(Intern Med 50: 2253-2254, 2011)

(DOI: 10.2169/internalmedicine.50.5715)

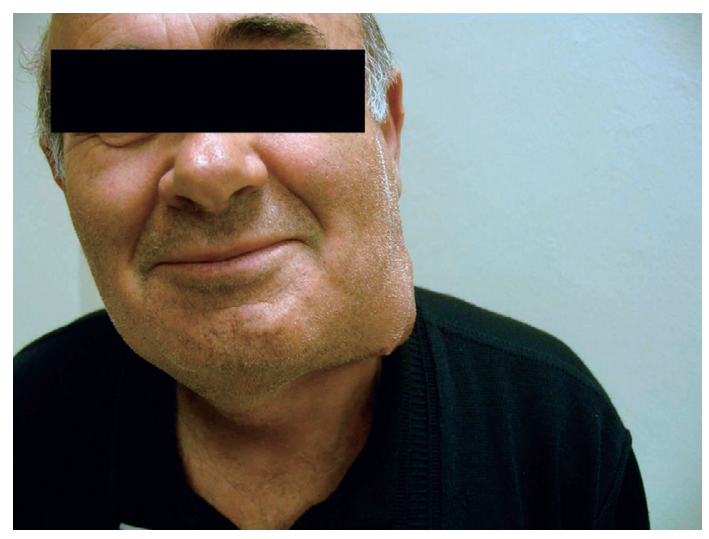

Picture 1.

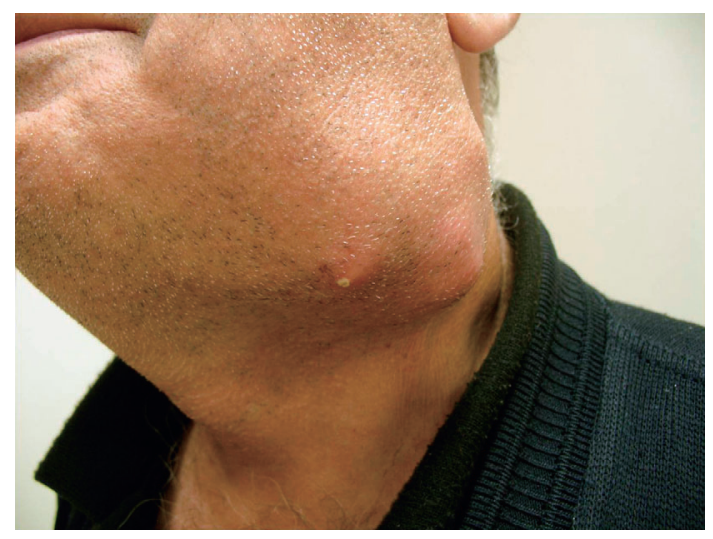

Picture 2.

A 63-year-old man presented with redness, pain and swelling in his left cervical region (Picture 1, 2). He described swelling of his left eye 25 days previously. After 3 days, the swelling on his left eye was resolved, but swelling in his left cervical region began to develop. His physical examination revealed swollen, sensitive and hard lymphadenopathies whose largest diameter was $33 \times 35 \mathrm{~mm}$ in his left cervical region. His body temperature was normal and laboratory findings were as follows: leucocytes $7,800 / \mathrm{mm}^{3}$, C-reactive protein $3 \mathrm{mg} / \mathrm{dL}$ (normal value $<5 \mathrm{mg} / \mathrm{dL}$ ), erythrocyte sedimentation rate $22 \mathrm{~mm} / \mathrm{h}$ and the other results were within normal ranges. There was no history of animal contact or insect bite, but he gave history of drinking spring water and using spring water to wash his face on a trip to a forest one month earlier. The patient was living in an endemic area for tularemia and also gave the history of similar cases in his village, thus we performed a serum microagglutination test for tularemia and it was positive at a titer of 1/2,560. He was diagnosed as oculoglandular tularemia. Due to the highly contagious nature of the pathogen, we did not obtain a clinical specimen and Doxycycline (100 mg two times per day) was prescribed for two weeks. At the end of two weeks as the enlarged lymph nodes were not completely shrunk, the treatment was continued for one more week, and they disappeared and the patient was doing well.

Tularemia is an endemic disease in Turkey and the oculoglandular form which is mainly acquired from contaminated water is the most frequent clinical form in our country (1). The definitive diagnosis is based on the culture of the causative agent. However, as such a culture requires special medium and laboratory-acquired infections can develop during the culture process, serological technique (microagglutination method) is used for diagnosis. In-house antigens prepared from F. tularensis NCTC 1,0857 (live vaccine strain) are used for microagglutination test and antibody titers over $1: 160$ or a four-fold or greater titer change are accepted as positive for serological diagnosis (2). Streptomycin is the first choice for treatment and must be used for at least 10 days. Doxycycline and ciprofloxacin are the other alternative treatment options (1).

The authors state that they have no Conflict of Interest (COI).

${ }^{1}$ Department of Infectious Diseases and Clinical Microbiology, Istanbul University, Cerrahpasa Medical School, Turkey and ${ }^{2}$ Florence Nightingale Hospital, Turkey

Received for publication April 27, 2011; Accepted for publication June 27, 2011

Correspondence to Dr. Yemisen Mücahit, yemisenmucahit@hotmail.com 
Intern Med 50: 2253-2254, 2011 DOI: 10.2169/internalmedicine.50.5715

\section{References}

1. Wilke A. Tularemi (Tularemia). ANKEM Derg 20: 222-226, 2006

(in Turkish).

2. Ellis J, Oyston PC, Gren M, Titball RW. Tularemia. Clin Microbiol Rev 15: 631-646, 2002.

(C) 2011 The Japanese Society of Internal Medicine

http://www.naika.or.jp/imindex.html 